\title{
Lateral approach versus conventional approach supraclavicular block for forearm surgeries. A prospective randomized controlled study
}

\author{
Amit Vadhel ${ }^{1}$, Devyani Desai, ${ }^{2, *}$, M R Upadhyay ${ }^{3}$ \\ ${ }^{1}$ Ex-Student, ${ }^{2}$ Associate Professor, ${ }^{3}$ Professor \& HOD, Dept. of Anaesthesia, SSG Hospital Government Medical College, \\ Vadodara, Gujarat, India
}

*Corresponding Author:

Email: devyani.dr@gmail.com

Received: $02^{\text {nd }}$ July, 2017

Accepted: $21^{\text {st }}$ September, 2017

\begin{abstract}
Background and Aims: Conventional technique of supraclavicular block is associated with direct injury to the vessels, nerves and pleura, which can be minimized with lateral approach. Here, we compared lateral with conventional approach supraclavicular block given for forearm surgeries.

Materials and Methods: After getting approval from ethical scientific committee, SSG hospital, Vadodara, this randomized prospective single blinded study was conducted from October 2014 to October 2015. 60 patients of either gender between 18 to 60 years, of ASA grade I and II undergoing forearm surgeries were enrolled. Those who refused, having anatomical distortion or infection of local site and pregnant patients were excluded. After doing randomization by computer method, Group $\mathrm{C}$ ( $\mathrm{n}=30$ ) received conventional and Group $\mathrm{L}(\mathrm{n}=30)$ received lateral approach supraclavicular block using nerve locator and total $35 \mathrm{ml}$ of Inj. Lignocaine with adrenaline (1:200000)7mg/kg, Inj. Bupivacaine $2 \mathrm{mg} / \mathrm{kg}$ with Inj. Sterile water was injected. Patients were evaluated for technical difficulty, characteristics of sensory and motor blockade, duration of postoperative analgesia and complications.

Results: Statistical analysis was done using student ' $\mathrm{t}$ ' test with Medcalc software. $\mathrm{P}<0.05$ was considered statistically significant. Supraclavicular block through lateral approach was easy to perform as less number of attempts were required. The characteristics of the sensory and motor block as well as duration of analgesia was similar in both the groups and incidence of vascular puncture was nil with lateral approach.
\end{abstract}

Conclusion: Lateral approach of supraclavicular block is a safe alternative to conventional approach.

Keywords: Supraclavicular block, Forearm orthopaedic surgeries.

\section{Introduction}

Brachial plexus anaesthesia is a technique well suited to surgical procedures for the upper limb. Disadvantages of the conventional supraclavicular block, as classically described, include an unacceptably high incidence of vascular puncture, pneumothorax (0.5-6\%), phrenic nerve block (40\%) and Horner's syndrome. ${ }^{1,2}$ The high incidence of phrenic nerve block dictates that the primary contraindication to supraclavicular block is respiratory insufficiency. ${ }^{3}$

To avoid these complications, a new approach to the supraclavicular block was described by Volker Hempel in $1981 .{ }^{4}$ Later on, it was modified by Dr. Dilip Kothari and termed it as "lateral approach". This technique involves needle to pass from lateral to medial side at an angle of $20^{\circ}$ to the skin and parallel to clavicle. As the advantages of this approach were appreciating, we decided to undertake this study to compare the effectiveness of lateral approach with conventional approach supraclavicular block.

\section{Materials and Methods}

After taking permission from scientific and ethical research committee of the institute, this prospective, randomised controlled, single blind clinical study was carried out in the department of anaesthesiology, government medical college and S.S.G. hospital, Vadodara from October 2014 to October 2015. 60 adult patients of American society of anaesthesiologists grade I and II, of either gender, between the age group of 1860 years, undergoing routine or emergency surgeries of forearm were enrolled. Patients having anatomical distortion of local site, bleeding disorders, psychiatric illness, localised infection, epilepsy, known hypersensitivity to local anaesthetics and pregnant patients were excluded from the study.

After thorough pre anaesthetic check-up, all patients underwent routine investigations including bleeding profile. X-ray chest and electrocardiogram were carried out if age is $>40$ years. They were explained in detail about the block procedure, visual analogue scale (VAS) and likely complications. Informed written consent in local language was taken. Patients were randomly divided (Randomization was done by computer method using www.randomizer.org.) into two groups: Group (C) patients received supraclavicular block by conventional approach and group (L) patients received supraclavicular block by lateral approach.

All Patients were kept nil by mouth adequately. On the day of surgery, base-line pulse rate, blood pressure, respiratory rate and $\mathrm{SpO}_{2}$ were recorded after taking the 
patient inside the operation theatre. Intravenous access was secured and Inj. DNS was started. Inj. Glycopyrrolate $0.2 \mathrm{mg}$, injection Ondansetron $4 \mathrm{mg}$ and injection Ranitidine $50 \mathrm{mg}$ intravenously was given 30 minutes prior to block.

\section{Position of patient}

Same for both the groups. Patient was laid supine with head turned to opposite side, shoulder depressed, arm by side of the chest. A folded sheet was placed below the shoulder at interscapular area to make field more prominent. The positive electrode of the nerve locator was attached on the ipsilateral arm. Under all aseptic and antiseptic precautions, all blocks were performed using 22G, 2 Stimuplex needle (B Braun) and a peripheral nerve locator (InMed). (Fig. 1)

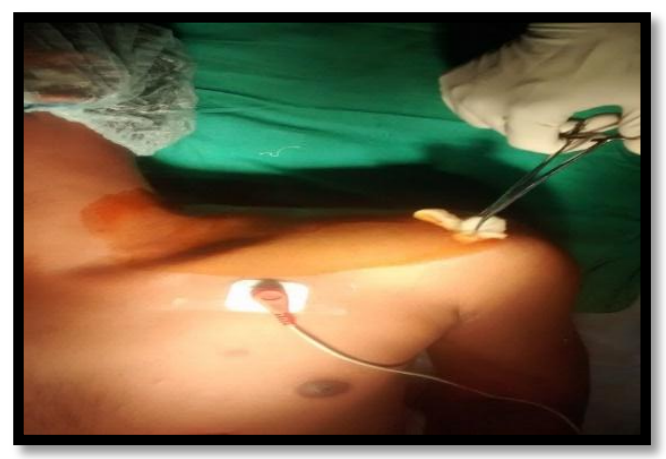

Fig. 1: Position of the patient

\section{Supraclavicular Block Procedure}

Group C (Conventional Approach): The subclavian artery pulsation is shifted by thumb of the left hand. Just lateral to it, Lignocaine 2cc was injected and an intradermal wheal was raised. Then, $22 \mathrm{~g}$ insulated needle attached to the negative electrode of the nerve locator after adjusting the internal current at $2 \mathrm{~mA}$, inserted in backward, inward and downward direction. After eliciting the finger and thumb flexion with stimulation, the current was reduced in steps till the presence of a muscle twitch with $0.5 \mathrm{~mA}$ and, the drug was injected after negative aspiration for air or blood. (Fig. 2)

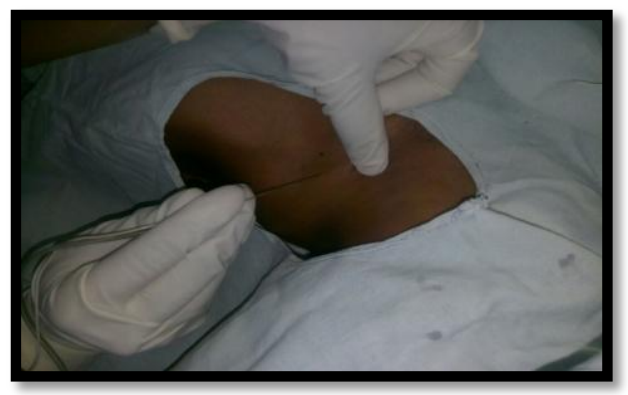

Fig. 2: Conventional approach
Group L (Lateral approach): After injecting 2\% Lignocaine at $1 \mathrm{~cm}$ above the junction of medial $2 / 3^{\text {rd }}$ and lateral $1 / 3^{\text {rd }}$ of clavicle, a $22 \mathrm{~g}$ needle attached to the negative electrode of the nerve locator was inserted and directed inward and medially at an angle of $20^{\circ}$ to the skin, parallel to the clavicle. After eliciting the distal motor response with stimulation, the current was reduced same as mentioned in group $\mathrm{C}$ and drug was administered after negative aspiration. In both the groups, Bupivacaine $(0.5 \%) 2 \mathrm{mg} / \mathrm{kg}+$ Lignocaine $(2 \%)$ $7 \mathrm{mg} / \mathrm{kg}$ with Adrenaline $(1: 200000)+$ sterile water to make the final volume $35 \mathrm{ml}$, was injected. (Fig. 3)

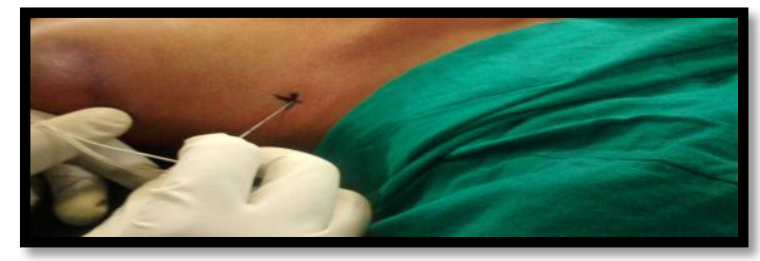

Fig. 3: Lateral approach

In cases of vascular puncture, needle was flushed with sterile water and pressure was applied for 5 minutes at the puncture site and block was reattempted.

Then after, patients were evaluated for the following parameters, I) Technical difficulties, II) Characteristics of sensory block, III) Characteristics of motor block i.e. Onset, extent and duration of block, IV) Tourniquet tolerance, V) Postoperative analgesia, VI) Hemodynamic monitoring, VII) Peri operative complications.

I. Technical difficulties were assessed by:

1. No. of attempt to locate the brachial plexus: Plexus reached in $1^{\text {st }}$ attempt is defined as easy and difficult if $>1$ attempt is required.

2. Block execution time is the time of insertion of needle to its removal on completion of procedure of giving block.

3. Distance from skin to brachial plexus: This was measured by the depth of needle travelled through the skin. Marking on the needle was done at the level of skin puncture just before its removal on completion of drug injection and then it was kept on ruler scale. (Fig. 4)

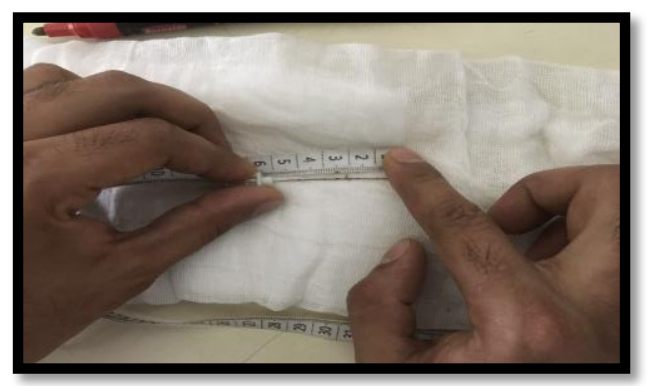

Fig. 4: Measuring the distance of needle from skin 
All patients were evaluated at every 2 minute interval for 30 minutes for following parameters.

II. Characteristics of sensory and motor block: The onset of sensory and motor block was defined as the time between last injection of local anaesthetics and feeling of dull sensation to pin prick and to loss of movement in any of the nerve distribution respectively. Extent of sensory block was assessed along the distribution of following nerves. Radial nerve-lateral side of dorsum of hand, median nerve - thenar eminence, ulnar nerve - $5^{\text {th }}$ finger, musculocutaneous nerve - lateral side of forearm. Grading was done by 3 point scale i.e. $0=$ normal sensation, 1 = dull sensation felt (analgesia), $2=$ loss of sensation (anaesthesia). ${ }^{6}$ The assessment of extent of motor block was done as follows: Radial nerve- thumb abduction, Median nerve - thumb opposition Ulnar nerve - thumb adduction, Musculocutaneous nerve - flexion of elbow. ${ }^{6}$ Grading was done by modified Bromage scale i.e. Grade 0: Normal motor function with full flexion and extension of elbow, wrist, and fingers, Grade 1: Decreased motor strength with ability to move the fingers only, Grade 2: Complete motor block with inability to move the finger. ${ }^{7}$ Duration of sensory and motor block was defined as the time interval between completion of local anaesthetic injection to return of sensation to pin prick and to complete recovery of motor function of all nerves, respectively.
IV. Tourniquet tolerance was assessed after tourniquet application as good: no discomfort, fair: tightening discomfort and poor: pain intolerance.

V. Postoperative analgesia - It was done with the help of visual analogue scale (VAS). Any patient having pain score $\geq 4$ on VAS was given analgesia in form of inj. Diclofenac Sodium $1.5 \mathrm{mg} / \mathrm{kg}$ intramuscularly. This was the endpoint of the study. Intraoperatively, pulse rate, blood pressure, respiratory rate, $\mathrm{SpO}_{2}$ were recorded periodically. Perioperative complications like vascular puncture, convulsions, pneumothorax, Horner's syndrome and phrenic nerve block were recorded if any.

Sample size estimation was done using Medcalc software using mean and standard deviation for the parameter "onset of analgesia" (11.77 $\pm 4.07 \mathrm{v} / \mathrm{s}$ $7.33 \pm 4.17$ minutes) with two-sided confidence interval $95 \%$ and $\alpha$ error 0.05 , power of the study $90 \%$ and $\beta$ error 0.10 , sample size came to be 38 . For better results, we decided to study 60 patients. A master chart was prepared to arrange the observed parameters of each case. Mean and standard deviation values were taken out. Analysis of variance (ANOVA) of the data for the various parameters was done using student's t-test for intra and inter-group comparison using Medcalc software. The significance of ANOVA was judged as follows-
1. $\mathrm{p}>0.05$ not significant
2. $\mathrm{p}<0.05$ significant
3. $\mathrm{p}<0.01$ highly significant

\section{Results}

Table I: Demographic data

\begin{tabular}{|l|c|c|c|}
\hline & Group C & Group L & P value \\
\hline Age(years) & $36.34 \pm 12.11$ & $38.96 \pm 11.8$ & 0.3958 \\
\hline Sex (M/F) & $25 / 5$ & $24 / 6$ & $0.97 / 0.99$ \\
\hline Weight (Kg) & $58 \pm 6.71$ & $59.4 \pm 6.31$ & 0.4085 \\
\hline ASA I/ II & $18 / 12$ & $15 / 15$ & $0.60 / 0.60$ \\
\hline $\begin{array}{l}\text { Duration of surgery } \\
\text { (minutes) }\end{array}$ & $86.33 \pm 10.02$ & $85.9 \pm 8.96$ & 0.5712 \\
\hline
\end{tabular}

60 patients were enrolled and none of the patients were excluded from the study. Both the groups were comparable to each other with regards to age, gender, weight, ASA physical status and duration of surgery ( $p>0.05)$ (Table I). Majority of patients were operated for radius ulna plating in both the groups.

Table II: Technical difficulties

\begin{tabular}{|c|c|c|c|c|c|c|}
\hline \multirow[t]{2}{*}{ Parameter } & & \multicolumn{2}{|c|}{ Group C } & \multicolumn{2}{|c|}{ Group L } & $P$ value \\
\hline & & No. & $\%$ & No. & $\%$ & \multirow{3}{*}{0.0191} \\
\hline \multirow[t]{2}{*}{ No. of attempts } & 1 & 12 & 40 & 22 & 73.33 & \\
\hline & $>1$ & 18 & 60 & 8 & 26.67 & \\
\hline $\begin{array}{l}\text { Block execution } \\
\text { time (min) }\end{array}$ & & $4.74 \pm 0.89$ & & $5.92 \pm 0.56$ & & $<0.0001$ \\
\hline $\begin{array}{l}\text { Distance from skin } \\
\text { to brachial plexus } \\
(\mathrm{cm})\end{array}$ & & $2.42 \pm 0.37$ & & $3.84 \pm 0.49$ & & $<0.0001$ \\
\hline
\end{tabular}

$60 \%$ of patients in group $\mathrm{C}$ and $26.67 \%$ of patients in group $\mathrm{L}(\mathrm{p}<0.05)$ required $>1$ attempt. The time required to execute block in group $\mathrm{C}$ was less, $4.74 \pm 0.89$ minutes while it was $5.92 \pm 0.56$ minutes in group $\mathrm{L}(\mathrm{p}<0.0001)$. 
Mean distance from skin to brachial plexus was also less being $2.42 \pm 0.37 \mathrm{~cm}$ in group $\mathrm{C}$ whereas, it was $3.84 \pm 0.49$ $\mathrm{cm}$ in group L. Difference was statistically highly significant $(\mathrm{p}<0.0001)$ (Table II). In group L, plexus was reached after $2.5 \mathrm{~cm}$ in all patients.

Table III: Characteristics of sensory block

\begin{tabular}{|l|c|c|c|c|c|}
\hline \multicolumn{1}{|c|}{ Parameter } & \multicolumn{2}{|c|}{ Group C } & \multicolumn{2}{c|}{ Group L } & P value \\
\hline Sensory onset (mins) & \multicolumn{2}{|c|}{$5.1 \pm 1.21$} & \multicolumn{2}{c|}{$5.66 \pm 1.29$} & 0.0601 \\
\hline \multirow{2}{*}{ Extent of block Grade } & \multicolumn{2}{|c|}{ Group C } & \multicolumn{2}{c|}{ Group L } & P value \\
\cline { 2 - 6 } & No & \% & No & \% & \\
\hline 0 & 00 & 00 & 00 & 00 & \multirow{2}{*}{0.7701} \\
\hline 1 & 07 & 23.33 & 09 & 30 & \\
\hline 2 & 23 & 76.66 & 21 & 70 & 0.8106 \\
\cline { 1 - 5 } $\begin{array}{l}\text { Duration of sensory } \\
\text { block }\end{array}$ & \multicolumn{2}{|c|}{$244 \pm 31.02$} & \multicolumn{2}{|c|}{$246.33 \pm 43$} & \\
\hline
\end{tabular}

The characteristics of sensory block were comparable in both the groups. (Table III) The time of sensory onset in group $\mathrm{C}$ was $5.1 \pm 1.21$ minutes while in group L, it was 5.66 \pm 1.29 minutes (p>0.05). $23(76.66 \%)$ patients in group C and $21(70 \%)$ patients in group L achieved grade 2 sensory block while 7 (23.33\%) patients in group C and $9(30 \%)$ patients in group L had grade 1 sensory block. In both the groups, incidence of failed block was nil ( $p>0.05)$. The duration of sensory block in group C was $244 \pm 31.02$ minutes and in group L was $246.33 \pm 43$ minutes $(\mathrm{p}>0.05)$.

Table IV: Characteristics of motor block (minutes)

\begin{tabular}{|l|c|c|c|c|c|}
\hline \multicolumn{1}{|c|}{ Parameter } & \multicolumn{2}{|c|}{ Group C } & \multicolumn{2}{c|}{ Group L } & P value \\
\hline $\begin{array}{l}\text { Motor onset } \\
\text { (minutes) }\end{array}$ & \multicolumn{2}{|c|}{$8.16 \pm 1.26$} & \multicolumn{2}{c|}{$8.56 \pm 1.75$} & 0.4104 \\
\hline $\begin{array}{l}\text { Modified } \\
\text { Bromage scale }\end{array}$ & \multicolumn{2}{|c|}{ Group C } & \multicolumn{2}{c|}{ Group L } & P value \\
\cline { 2 - 5 } & No. & $\%$ & No. & $\%$ & \\
\hline Grade 0 & 00 & 00 & 00 & 00 & - \\
\hline Grade 1 & 11 & 36.66 & 10 & 33.33 & 0.9998 \\
\hline Grade 2 & 19 & 63.33 & 20 & 66.67 & 0.9996 \\
\hline $\begin{array}{l}\text { Duration of } \\
\text { motor block }\end{array}$ & $209 \pm 27.33$ & $198.83 \pm 35.85$ & 0.2216 \\
\hline
\end{tabular}

We did not find any difference in the motor blockade characteristics between both the groups. The time of motor onset in group $C$ was $8.16 \pm 1.26$ minutes whereas in group $\mathrm{L}$ was $8.56 \pm 1.75$ minutes. $(p>0.05)$. $19(63.33 \%)$ patients in Group C and 20 (67\%) patients in Group L achieved grade 2 motor block ( $p>0.05$ ). The mean duration of motor block was $209 \pm 27.33$ minutes for group C, whereas $198.83 \pm 35.8$ minutes in group L ( $>0.05)$.

Inj. Propofol $1.5 \mathrm{mg} / \mathrm{kg}$ was given to supplement anaesthesia during skin incision or during manipulation of fractured site, in 5 cases in group $C$ and 7 cases in group $L(p>0.05)$. None of the patient from our study complained about tourniquet discomfort intraoperatively.

Table V: Duration of postoperative analgesia (hours)

\begin{tabular}{|l|c|c|c|}
\hline Duration & Group C & Group L & P value \\
\hline $\begin{array}{l}\text { Duration of postoperative } \\
\text { analgesia }\end{array}$ & $6.96 \pm 1.12$ & $7.46 \pm 1.65$ & 0.1750 \\
\hline
\end{tabular}

The mean duration of postoperative analgesia being $7.46 \pm 1.65$ hours in group $\mathrm{L}$ and $6.96 \pm 1.12$ hours in group $\mathrm{C}$ was comparable ( $>>0.05)$ (Table V). All patients in both the groups remained haemodynamically stable throughout the perioperative period.

Table VI: Complications

\begin{tabular}{|l|c|c|c|c|c|}
\hline \multirow{2}{*}{ Complications } & \multicolumn{2}{|c|}{ Group C } & \multicolumn{2}{c|}{ Group L } & \multirow{2}{*}{ P value } \\
\cline { 2 - 5 } & No. & \% & No. & \% & \\
\hline Vascular puncture & 06 & 20 & 00 & 00 & 0.0314 \\
\hline Convulsions & 00 & 00 & 00 & 00 & - \\
\hline Pneumothorax & 00 & 00 & 00 & 00 & - \\
\hline Horner's syndrome & 00 & 00 & 00 & 00 & - \\
\hline Phrenic nerve block & 01 & 3.33 & 00 & 00 & 0.992 \\
\hline
\end{tabular}


In group $\mathrm{C}$, incidence of vascular puncture was $20 \%$ compared to nil in group L. Difference was statistically significant $(\mathrm{p}<0.05)$. One patient developed symptomatic phrenic nerve block in group C. No other complications like convulsion, pneumothorax or Horner syndrome were noted in either of the groups (Table VI).

\section{Discussion}

Rapid onset and reliable anaesthesia makes the brachial plexus blockade most suitable technique for upper limb anaesthesia. Various approaches and many modified techniques have been described to avoid complications associated with it. ${ }^{8}$ The needle insertion close to the subclavian artery and in a backward, inward and downward direction carries risk of puncturing the pleural dome as well as vascular structures in conventional approach. The contact of the needle with plexus sheath forms more of perpendicular angle which also carries risk of nerve injury. ${ }^{3}$

In our study, it was easy to perform block as less number of attempts were required with lateral approach. The higher number of attempts with conventional approach was because of higher number of vascular punctures and less space for needle manipulation as needle was inserted with proximity to vessels. A Kumar et al (2012) studied number of times the needle was to be redirected as a parameter for technical difficulty and found that it was technically easy in $48 \%$ of patients with lateral approach. ${ }^{9}$ It was easy to perform block after getting an expertise over it with time.

Due to requirement of more time to achieve distal contractions of hand muscles, it took long time to execute the block with lateral approach. P K Prasad et al (2014) also observed the same. ${ }^{10}$ Mean distance from skin to brachial plexus was $3.84 \pm 0.49 \mathrm{~cm}$ in group L suggests that $5 \mathrm{~cm}$ long needle is needed to reach up to the plexus through lateral approach. The greater distance of skin to brachial plexus in lateral approach was because of long and lateral track of needle (A Kumar et al 2012). ${ }^{9}$

While observing the onset of sensory block, P K Prasad et al (2014) also found no statistical difference in both the groups, ${ }^{10}$ but A Kumar et al (2012) found significant difference between two approaches (7.33 \pm 4.17 minutes v/s $11.77 \pm 4.07$ minutes, $\mathrm{p}<0.05){ }^{9}$ The reason being not mentioned by them.

Complete sensory block was achieved in $76.66 \%$ of patients in group $\mathrm{C}$ and $70 \%$ of patients in group L. Remaining patients developed grade I sensory block. To achieve a higher success rate, Franco et al (2004) recommended to use $0.5 \mathrm{~mA}$ as minimal stimulatory currents to obtain a motor response (finger flexion or extension) prior to injection of local anaesthetics. Furthermore, no difference was noted in terms of onset or duration of anaesthesia. ${ }^{11}$ In majority of grade 1 sensory block, ulnar nerve sparing was found with both the approaches, i.e. 5 cases in group $\mathrm{C}$ and 7 cases in group L. Failure to block the lower trunk, which subsequently results in inadequate ulnar nerve anaesthesia as lower trunk commonly lies in the 'corner pocket' between the first rib inferiorly, the supraclavicular artery medially and the nerves superiorly frequently produces incomplete block while using the supraclavicular approach. ${ }^{12}$

In this regard, our results are in consonance with A Kumar et al (2012) ${ }^{9}$ and Dr Dilip Kothari (2003). ${ }^{5}$ The higher success rate in lateral approach is because of blockage of all the nerves of the plexus with the same frequency as at this level trunks and cords are bundled together and nearly equal distance is involved in the spread of local anaesthetics to the nerve structure.

P K Prasad et al (2014) ${ }^{10}$ observed no difference in duration of sensory block between two groups. But, A Kumar et al (2012) found longer duration of sensory block in lateral approach group than in conventional approach but he did not mention the reason $(180.3 \pm 38.43$ minutes $\mathrm{v} / \mathrm{s} 152.8 \pm 31.3$ minutes, $\mathrm{p}<0.05) .{ }^{9}$

Contrast to our results, A Kumar et al (2012) observed complete motor block in only $42 \%$ patients in group C while D K Sahu et al (2010) found complete motor loss in higher number of cases $(90 \%)$ with lateral approach. ${ }^{9,13}$ A Kumar et al (2012) ${ }^{7}$ also observed longer duration of motor block using lateral approach $(176.57 \pm 33.92 \mathrm{v} / \mathrm{s} 154.2 \pm 31.75)$. As observed by P K Prasad et al, we were unable to find any difference in the duration of postoperative analgesia between both the groups. ${ }^{10}$

In our study, the incidence of vascular puncture was nil while performing the block through lateral approach. D K Sahu et al (2010) ${ }^{13}$ found $24 \%$ cases, Dr. Dilip Kothari $(2003)^{5}$ and A Kumar et al $(2012)^{9}$ reported 6\% cases and P K Prasad et al (2014) ${ }^{10}$ found $4 \%$ cases of vessel puncture during the procedure of lateral approach.

1 patient developed symptomatic phrenic nerve block in group C. He complained having discomfort during deep inspiration. On auscultation, breath sounds were decreased on right side. $\mathrm{Spo}_{2}$ remained unchanged. $A$ chest $X$ ray revealed right hemidiaphragm at the level of 8 rib i.e. de novo flattening of the ipsilateral hemidiaphragm. Patient was shifted to PACU for observation where he settled down with reassurance. Oxygen supplementation with nonrebreathing mask was given. There was complete remission of the symptoms after 2 hours.

The location of the phrenic nerve is very close to the brachial plexus in the neck, in front of the anterior scalene muscle and separated from the plexus only by a fascia. By diffusing anaesthetic solution by retrograde spread, it can reached easily when supraclavicular techniques are used. ${ }^{13} \mathrm{P} \mathrm{H} \mathrm{K} \mathrm{Mak} \mathrm{et} \mathrm{al} \mathrm{assessed} \mathrm{the}$ diaphragm function via ultrasonography after conventional supraclavicular block and showed complete paralysis of hemidiaphragm in $50 \%$ of the patients though all patients remained asymptomatic with normal oxygen saturation on room air. ${ }^{14} \mathrm{He}$ also 
suggested to use modification of supraclavicular block while using it in obese and patients with respiratory morbidity as incidence of distress was high with such patients. Volker Hempel $(1983)^{4}$ demonstrated 1 case each of phrenic nerve block and recurrent laryngeal nerve block with lateral approach.

No other complications were noted in either of the group in our study. Unlike our results, $20 \%$ patients with conventional and $12 \%$ patients with lateral approach in the study done by P K Prasad et al (2014) had postoperative nausea and vomiting. They also documented 1 case of Horner syndrome with conventional approach. ${ }^{10}$

From our study, it can be concluded that supraclavicular block through lateral approach was easy to perform as it required less number of attempts but took long time to execute. It required higher depth of needle insertion compared to conventional approach. Characteristics of the sensory and motor block as well as the duration of analgesia remained unchanged. The incidence of complications including vascular puncture was nil while using lateral approach. Thus, lateral approach of supraclavicular brachial plexus block is easier and safer alternative to conventional approach for forearm surgeries.

\section{References}

1. Kumar A, Gupta R, Bhardwaj A, Madan D. Delayed pneumothorax after supraclavicular block. J Anaesthesiol Clin Pharmacol. 2011;27:121-2.

2. Wedel DJ. Nerve blocks. In: Cucchiara R F, Miller ED, Reves JG, Roizen MF, editors. Anaesthesia. 5th edition. California: Churchill livingstone; 2000:1520-48.

3. Joseph M Neal, James R. Hebl, Gerancher, Quinn H Hogan. Brachial plexus anaesthesia; Essentials of our current understanding. Reg anaesth pain med 2002; 27:402-28.

4. Volker Hempel, Meno van Finc and Elmar Baumgartnerf. A longitudinal supraclavicular approach to the brachial plexus for insertion of plastic canulas; Anesth Analg 1981;60:3525.

5. Dr. Dilip Kothari. Supraclavicular brachial plexus block: A new approach. Indian journal of anaesthesia 2003;47:287-8.

6. R. G. Pathak, Anand P. Satkar, Rajendra N. Khade. Supraclavicular brachial plexus block with and without Dexamethasone; International journal of scientific and research publication 2012;12:1-5.

7. Sarita S Swami, Varshali M Keniya, Sushma D Ladi, Ruchika Rao Comparison of dexmedetomidine and clonidine (a2 agonist drugs) as an adjuvant to local anaesthesia in supraclavicular brachial plexus block: A randomised double-blind prospective study. Indian Journal of Anaesthesia 2012;56:243-9.

8. Harold J Ball. A modified supraclavicular approach. Anaesthesia 1962;17:269-73.

9. A Kumar, B Shadangi, J Agarwal, V Agnihotri. Lateral approach of supraclavicular brachial plexus as a better alternative to conventional supraclavicular brachial plexus block. The int J anesthesiol 2012;30:1-5.

10. Pothula Krishna Prasad, B. Sowbhagya Lakshmi, Paleti Sophia, Vanapalli Sirisha. Comparison of lateral approach with conventional approach of supraclavicular brachial plexus block: a prospective randomized study. Journal of evolution of medical and dental science 2014;3:8661-9.
11. Franco CD, Domashevich V, Voronov G, Rafizad AB, Jelev TJ. The supraclavicular block with a nerve stimulator: to decrease or not to decrease, that is the question. Anesth Analg 2004;98:1167-71.

12. Alan Macfarlene. Ultrasound guided supraclavicular block. The journal of New York school of regional anesthesia 2009;12:6-10.

13. D K Sahu, Anjana Sahu. Lateral approach for supraclavicular brachial plexus block. Indian Journal of anaesthesia 2010;54:215-218.

14. P H K Mak, M G Irwin, C G C Ooi, B F M Chow. Incidence of diaphragmatic paralysis following supraclavicular brachial plexus block and its effect on pulmonary function. Anaesthesia 2001;56:352-6. 